\title{
Fuzzy fixed point results of generalized almost F-contraction
}

\author{
Abdullah Eqal Al-Mazrooei, Jamshaid Ahmad* \\ Department of Mathematics, University of Jeddah, P. O. Box 80327, Jeddah 21589, Saudi Arabia.
}

\begin{abstract}
The aim of this paper is to obtain some common $\alpha$-fuzzy fixed points for fuzzy mappings under almost F-contraction in the setting of metric space. In this way we generalize, unify, and complement fuzzy fixed point results of literature. As an application, we derive some multivalued fixed point theorems as a direct consequence of our main results. We also provide a non trivial example to show the significance of the investigation of this paper.
\end{abstract}

Keywords: $\alpha$-Fuzzy fixed points, F-contraction, multivalued mapping, metric space.

2010 MSC: 47H10, 54H25, 54A40.

(C)2018 All rights reserved.

\section{Introduction}

In the theory of metric spaces, Banach fixed point theorem [12] is an important tool which guarantees the existence and uniqueness of fixed points of certain self mappings. It actually provides a constructive method to find fixed points. This theorem was first stated by a Polish Mathematician Stefan Banach in 1922.

There are many generalizations of Banach fixed point theorem in the literature. One of the most interesting generalizations is almost contraction which was first given by Berinde [13,14]. Berinde studied many kinds of contraction mappings and gave the concept of almost contraction in following way.

Definition $1.1([13])$. Let $(X, d)$ be a metric space. A mapping $T: X \rightarrow X$ is called an almost contraction if there exists a constant $\lambda \in[0,1)$ and some $L \geqslant 0$ such that

$$
d(T x, T y) \leqslant \lambda d(x, y)+\operatorname{Ld}(y, T x)
$$

for all $x, y \in X$.

He also generalized the above almost contraction as follows.

\footnotetext{
${ }^{*}$ Corresponding author

Email address: jamshaid_jasim@yahoo.com (Jamshaid Ahmad)

doi: $10.22436 /$ jmcs.018.02.08
}

Received 2017-04-28 
Definition $1.2([14])$. Let $(X, d)$ be a metric space. A mapping $T: X \rightarrow X$ is said to be generalized almost contraction if there exists a constant $\lambda \in[0,1)$ and some $L \geqslant 0$ such that

$$
d(T x, T y) \leqslant \lambda d(x, y)+\operatorname{Lmin}\{d(x, T x), d(y, T y), d(x, T y), d(y, T x)\}
$$

for all $x, y \in X$.

A new approach in the theory of fixed points was recently given by Wardowski [29]. In his article, he extended the contractive condition on the mapping and introduced new type of contractions called F-contractions. He proved a new fixed point theorem regarding F-contractions in the context of complete metric spaces. Wardowski defined F-contraction as follows.

Definition 1.3. Let $(X, d)$ be a metric space. A mapping $T: X \rightarrow X$ is said to be a F-contraction if there exists $\tau>0$ such that for $x, y \in X$,

$$
d(T x, T y)>0 \Longrightarrow \tau+F(d(T x, T y)) \leqslant F(d(x, y))
$$

where $\mathrm{F}: \mathbb{R}^{+} \rightarrow \mathbb{R}$ is a mapping satisfying the following conditions

$\left(F_{1}\right) F$ is strictly increasing;

(F $\left.F_{2}\right)$ for all sequence $\left\{\alpha_{n}\right\} \subseteq R^{+}, \lim _{n \rightarrow \infty} \alpha_{n}=0$ if and only if $\lim _{n \rightarrow \infty} F\left(\alpha_{n}\right)=-\infty$;

$\left(F_{3}\right)$ there exists $0<k<1$ such that $\lim _{n \rightarrow 0^{+}} \alpha^{k} F(\alpha)=0$.

Later on Altun et al. [7] modified the above definitions by adding a general condition $\left(\mathrm{F}_{4}\right)$ which is given in this way:

$\left(F_{4}\right) F(\inf A)=\inf F(A)$ for all $A \subset(0, \infty)$ with $\inf A>0$.

Altune et al. [6] used the concept of F-contraction and defined the notion of multivalued almost F-contraction to prove some fixed point results in complete metric spaces.

We represent the set of all functions $F: \mathbb{R}^{+} \rightarrow \mathbb{R}$ satisfying conditions $\left(\mathrm{F}_{1}\right)-\left(\mathrm{F}_{4}\right)$ by $\digamma$.

For more details on F-contraction, we refer the reader to [3, 4, 19-23, 28].

On the other hand, Heilpern [18] used the concept of fuzzy set to introduced a class of fuzzy mappings, which is a generalization of the set-valued mapping, and proved a fixed point theorem for fuzzy contraction mappings in metric linear space in 1981. It is worth noting that the result announced by Heilpern [18] is a fuzzy extension of the Banach contraction principle. Subsequently, several other authors have studied existence of fixed points of fuzzy mappings, see [2, 5, 8-11, 15-17, 25, 26, 30].

Let $(X, d)$ be a metric space and $C B(X)$ the family of nonempty, closed, and bounded subsets of $X$. For $A, B \in C B(X)$, define

$$
H(A, B)=\max \left\{\sup _{a \in A} d(a, B), \sup _{b \in B} d(b, A)\right\},
$$

where

$$
d(x, A)=\inf _{y \in A} d(x, y)
$$

A fuzzy set in $X$ is a function with domain $X$ and values in $[0,1], I^{X}$ is the collection of all fuzzy sets in $X$. If $A$ is a fuzzy set and $x \in X$, then the function values $A(x)$ is called the grade of membership of $x$ in $A$. The $\alpha$-level set of $A$ is denoted by $[A]_{\alpha}$ and is defined as follows:

$$
[A]_{\alpha}=\{x: A(x) \geqslant \alpha\} \text { if } \alpha \in(0,1], \quad[A]_{0}=\overline{\{x: A(x)>0\}} .
$$

Here $\bar{B}$ denotes the closure of the set $B$. Let $\mathfrak{I}(X)$ be the collection of all fuzzy sets in a metric space $X$. For $A, B \in \mathfrak{I}(X), A \subset B$ means $A(x) \leqslant B(x)$ for each $x \in X$. We denote the fuzzy set $X_{\{x\}}$ by $\{x\}$ unless 
and until it is stated, where $\chi_{\{x\}}$ is the characteristic function of the crisp set $A$. If there exists an $\alpha \in[0,1]$ such that $[A]_{\alpha},[B]_{\alpha} \in C B(X)$, then define

$$
p_{\alpha}(A, B)=\inf _{x \in[A]_{\alpha}, y \in[B]_{\alpha}} d(x, y), \quad D_{\alpha}(A, B)=H\left([A]_{\alpha},[B]_{\alpha}\right) .
$$

If $[A]_{\alpha},[B]_{\alpha} \in C B(X)$ for each $\alpha \in[0,1]$, then define

$$
p(A, B)=\sup _{\alpha} p_{\alpha}(A, B), \quad d_{\infty}(A, B)=\sup _{\alpha} D_{\alpha}(A, B) .
$$

We write $p(x, B)$ instead of $p(\{x\}, B)$. A fuzzy set $A$ in a metric linear space $V$ is said to be an approximate quantity if and only if $[A]_{\alpha}$ is compact and convex in $V$ for each $\alpha \in[0,1]$ and $\sup _{x \in V} A(x)=1$. The collection of all approximate quantities in $V$ is denoted by $W(V)$. Let $X$ be an arbitrary set and $Y$ be a metric space. A mapping $T$ is called fuzzy mapping if $T$ is a mapping from $X$ into $\mathfrak{I}(Y)$. A fuzzy mapping $T$ is a fuzzy subset on $X \times Y$ with membership function $T(x)(y)$. The function $T(x)(y)$ is the grade of membership of $y$ in $T(x)$.

Definition 1.4. Let $S, T$ be fuzzy mappings from $X$ into $\mathfrak{I}(X)$. A point $u \in X$ is called an $\alpha$-fuzzy fixed point of $T$ if there exists $\alpha \in[0,1]$ such that $u \in[T u]_{\alpha}$. The point $u \in X$ is called a common $\alpha$-fuzzy fixed point of $S$ and $T$ if there exists $\alpha \in[0,1]$ such that $u \in[S u]_{\alpha} \cap[T u]_{\alpha}$. When $\alpha=1$, it is called a common fixed point of fuzzy mappings.

The aim of this article is to prove some common $\alpha$-fuzzy fixed points for fuzzy mappings for almost F-contraction in the context of complete metric space to generalize some known results of literature.

For the sake of convenience, we first state some known results for subsequent use in the next section.

Lemma 1.5 ([24]). Let $(X, d)$ be a metric space and $A, B \in C B(X)$, then for each $a \in A$,

$$
d(a, B) \leqslant H(A, B) .
$$

Lemma 1.6 ([8]). Let $\mathrm{V}$ be a metric linear space, $\mathrm{T}: \mathrm{V} \rightarrow \mathrm{W}(\mathrm{V})$ be a fuzzy mapping, and $\mathrm{x}_{0} \in \mathrm{V}$. Then there exists $\mathrm{x}_{1} \in \mathrm{V}$ such that $\left\{\mathrm{x}_{1}\right\} \subset \mathrm{T}\left(\mathrm{x}_{0}\right)$.

\section{Main results}

Theorem 2.1. Let $(X, d)$ be a complete metric space and let $S, T$ be fuzzy mappings from $X$ into $\mathfrak{I}(X)$ and for each $x \in X$, there exist $\alpha_{S}(x), \alpha_{T}(y) \in(0,1]$ such that $[S x]_{\alpha_{S}(x)},[T y]_{\alpha_{T}(y)}$ are nonempty, closed, and bounded subsets of $X$. If there exists some $\mathrm{F} \in \digamma, \tau>0$, and $\mathrm{L} \geqslant 0$ such that

$$
\tau+F\left(H\left([S x]_{\alpha_{S}(x)},[T y]_{\alpha_{T}(y)}\right)\right) \leqslant F(d(x, y))+L(M(x, y))
$$

for all $x, y \in X$ with $\mathrm{H}\left([S x]_{\alpha_{S}(x)},[\mathrm{T} y]_{\alpha_{T}(y)}\right)>0$, where

$$
M(x, y)=\min \left\{d\left(x,[S x]_{\alpha_{S}(x)}\right), d\left(y,[T y]_{\alpha_{T}(y)}\right), d\left(x,[T y]_{\alpha_{T}(y)}\right), d\left(y,[S x]_{\alpha_{S}(x)}\right)\right\},
$$

then there exists some $\mathrm{u} \in[\mathrm{Su}]_{\alpha_{S}(\mathrm{u})} \cap[\mathrm{Tu}]_{\alpha_{\mathrm{T}}(\mathrm{u})}$.

Proof. Let $x_{0}$ be an arbitrary point in $X$, then by hypotheses there exists $\alpha_{S}\left(x_{0}\right) \in(0,1]$ such that $\left[S x_{0}\right]_{\alpha_{S}\left(x_{0}\right)}$ is a nonempty, closed, and bounded subset of $X$. Let $x_{1} \in\left[S x_{0}\right]_{\alpha_{S}\left(x_{0}\right)}$. For this $x_{1}$ there exists $\alpha_{T}\left(x_{1}\right) \in(0,1]$ such that $\left[T x_{1}\right]_{\alpha_{T}\left(x_{1}\right)}$ is a nonempty, closed, and bounded subset of $X$. By Lemma 1.5, $\left(F_{1}\right)$, and (2.1), we have

$$
\tau+\mathrm{F}\left(\mathrm{d}\left(\mathrm{x}_{1},\left[\mathrm{~T} x_{1}\right]_{\alpha_{\mathrm{T}}\left(\mathrm{x}_{1}\right)}\right)\right) \leqslant \tau+\mathrm{F}\left(\mathrm{H}\left(\left[S \mathrm{x}_{0}\right]_{\alpha_{S}\left(\mathrm{x}_{0}\right)},\left[\mathrm{T} \mathrm{x}_{1}\right]_{\alpha_{\mathrm{T}}\left(\mathrm{x}_{1}\right)}\right)\right) \leqslant \mathrm{F}\left(\mathrm{d}\left(\mathrm{x}_{0}, \mathrm{x}_{1}\right)\right)+\mathrm{L}\left(\mathrm{M}\left(\mathrm{x}_{0}, \mathrm{x}_{1}\right)\right),
$$


where

$$
M\left(x_{0}, x_{1}\right)=\min \left\{d\left(x_{0},\left[S x_{0}\right]_{\alpha_{S}\left(x_{0}\right)}\right), d\left(x_{1},\left[T x_{1}\right]_{\alpha_{T}\left(x_{1}\right)}\right), d\left(x_{0},\left[T x_{1}\right]_{\alpha_{T}\left(x_{1}\right)}\right), d\left(x_{1},\left[S x_{0}\right]_{\alpha_{S}\left(x_{0}\right)}\right)\right\} .
$$

From $\left(\mathrm{F}_{4}\right)$, we know that

$$
F\left(d\left(x_{1},\left[T x_{1}\right]_{\alpha_{T}\left(x_{1}\right)}\right)\right)=\inf _{y \in\left[T x_{1}\right]_{\alpha_{T}\left(x_{1}\right)}} F\left(d\left(x_{1}, y\right)\right)
$$

Thus

$$
\tau+\inf _{y \in\left[T x_{1}\right]_{\alpha_{T}\left(x_{1}\right)}} F\left(d\left(x_{1}, y\right)\right) \leqslant F\left(d\left(x_{0}, x_{1}\right)\right)+\operatorname{Lin}\left\{\begin{array}{c}
d\left(x_{0},\left[S x_{0}\right]_{\alpha_{S}\left(x_{0}\right)}\right), d\left(x_{1},\left[T x_{1}\right]_{\alpha_{T}\left(x_{1}\right)}\right), \\
d\left(x_{0},\left[T x_{1}\right]_{\alpha_{T}\left(x_{1}\right)}\right), d\left(x_{1},\left[S x_{0}\right]_{\alpha_{S}\left(x_{0}\right)}\right)
\end{array}\right\} .
$$

Then, there exists $x_{2} \in\left[T x_{1}\right]_{\alpha_{T}\left(x_{1}\right)}$ such that

$$
\tau+F\left(d\left(x_{1}, x_{2}\right)\right) \leqslant F\left(d\left(x_{0}, x_{1}\right)\right)+\operatorname{Lmin}\left\{d\left(x_{0}, x_{1}\right), d\left(x_{1}, x_{2}\right), d\left(x_{0}, x_{2}\right), d\left(x_{1}, x_{1}\right)\right\}=F\left(d\left(x_{0}, x_{1}\right)\right) .
$$

For this $x_{2}$ there exists $\alpha_{S}\left(x_{2}\right) \in(0,1]$ such that $\left[S x_{2}\right]_{\alpha_{S}\left(x_{2}\right)}$ is a nonempty, closed, and bounded subset of $X$. By Lemma 1.5, $\left(F_{1}\right)$, and (2.1), we have

$$
\begin{aligned}
\tau+\mathrm{F}\left(\mathrm{d}\left(\mathrm{x}_{2},\left[\mathrm{~S} \mathrm{x}_{2}\right]_{\alpha_{S}\left(\mathrm{x}_{2}\right)}\right)\right) & \leqslant \tau+\mathrm{F}\left(\mathrm{H}\left(\left[\mathrm{T} x_{1}\right]_{\alpha_{\mathrm{T}}\left(\mathrm{x}_{1}\right)},\left[\mathrm{S} x_{2}\right]_{\alpha_{S}\left(x_{2}\right)}\right)\right) \\
& =\tau+\mathrm{F}\left(\mathrm{H}\left(\left[S x_{2}\right]_{\alpha_{S}\left(x_{2}\right)},\left[\mathrm{T} x_{1}\right]_{\alpha_{\mathrm{T}}\left(x_{1}\right)}\right)\right) \leqslant \mathrm{F}\left(\mathrm{d}\left(\mathrm{x}_{2}, \mathrm{x}_{1}\right)\right)+\mathrm{L}\left(\mathrm{M}\left(\mathrm{x}_{2}, \mathrm{x}_{1}\right)\right),
\end{aligned}
$$

where

$M\left(x_{2}, x_{1}\right)=\min \left\{d\left(x_{2}, x_{1}\right), d\left(x_{2},\left[S x_{2}\right]_{\alpha_{S}\left(x_{2}\right)}\right), d\left(x_{1},\left[T x_{1}\right]_{\alpha_{T}\left(x_{1}\right)}\right), d\left(x_{2},\left[T x_{1}\right]_{\alpha_{T}\left(x_{1}\right)}\right), d\left(x_{1},\left[S x_{2}\right]_{\alpha_{S}\left(x_{2}\right)}\right)\right\}$.

From $\left(\mathrm{F}_{4}\right)$, we know that

$$
F\left[d\left(x_{2},\left[S x_{2}\right]_{\alpha_{S}\left(x_{2}\right)}\right)\right]=\inf _{y_{1} \in\left[S x_{2}\right]_{\alpha_{S}\left(x_{2}\right)}} F\left(d\left(x_{2}, y_{1}\right)\right)
$$

Thus

$$
\tau+\inf _{y_{1} \in\left[S x_{2}\right]_{\alpha_{S}\left(x_{2}\right)}} F\left(d\left(x_{2}, y_{1}\right)\right) \leqslant F\left(d\left(x_{2}, x_{1}\right)\right)+\operatorname{Lin}\left\{\begin{array}{c}
d\left(x_{2}, x_{1}\right), d\left(x_{2},\left[S x_{2}\right]_{\alpha_{S}\left(x_{2}\right)}\right), d\left(x_{1},\left[T x_{1}\right]_{\alpha_{T}\left(x_{1}\right)}\right), \\
d\left(x_{2},\left[T x_{1}\right]_{\alpha_{T}\left(x_{1}\right)}\right), d\left(x_{1},\left[S x_{2}\right]_{\alpha_{S}\left(x_{2}\right)}\right)
\end{array}\right\} .
$$

Then, there exists $x_{3} \in\left[S x_{2}\right]_{\alpha_{S}\left(x_{2}\right)}$ such that

$$
\tau+F\left(d\left(x_{2}, x_{3}\right)\right) \leqslant F\left(d\left(x_{1}, x_{2}\right)\right)+\operatorname{Lmin}\left\{d\left(x_{2}, x_{1}\right), d\left(x_{2}, x_{3}\right), d\left(x_{1}, x_{2}\right), d\left(x_{2}, x_{2}\right), d\left(x_{1}, x_{3}\right)\right\},
$$

which implies

$$
\tau+F\left(d\left(x_{2}, x_{3}\right)\right) \leqslant F\left(d\left(x_{1}, x_{2}\right)\right) .
$$

So, continuing recursively, we obtain a sequence $\left\{x_{n}\right\}$ in $X$ such that $x_{2 n+1} \in\left[S x_{2 n}\right]_{\alpha_{S}\left(x_{2 n}\right)}$ and $x_{2 n+2} \in$ $\left[T x_{2 n+1}\right]_{\alpha_{T}\left(x_{2 n+1}\right)}$ and

$$
\tau+F\left(d\left(x_{2 n+1}, x_{2 n+2}\right)\right) \leqslant F\left(d\left(x_{2 n}, x_{2 n+1}\right)\right)
$$

and

$$
\tau+F\left(d\left(x_{2 n+2}, x_{2 n+3}\right)\right) \leqslant F\left(d\left(x_{2 n+1}, x_{2 n+2}\right)\right)
$$

for all $n \in \mathbb{N}$. From (2.2) and (2.3), we have

$$
\tau+F\left(d\left(x_{n}, x_{n+1}\right)\right) \leqslant F\left(d\left(x_{n-1}, x_{n}\right)\right) .
$$


Therefore,

$$
F\left(d\left(x_{n}, x_{n+1}\right)\right) \leqslant F\left(d\left(x_{n-1}, x_{n}\right)\right)-\tau \leqslant F\left(d\left(x_{n-2}, x_{n-1}\right)\right)-2 \tau,
$$

which implies

$$
F\left(d\left(x_{n}, x_{n+1}\right)\right) \leqslant \cdots \leqslant F\left(d\left(x_{0}, x_{1}\right)\right)-n \tau .
$$

Letting $n \rightarrow \infty$ in above inequality, we obtain $\lim _{n \rightarrow \infty} F\left(d\left(x_{n}, x_{n+1}\right)\right)=-\infty$ that together with $\left(F_{2}\right)$ gives

$$
\lim _{n \rightarrow \infty} d\left(x_{n}, x_{n+1}\right)=0 .
$$

Now by $\left(F_{3}\right)$, there exists $h \in(0,1)$ such that

$$
\lim _{n \rightarrow \infty}\left[d\left(x_{n}, x_{n+1}\right)\right]^{h} F\left(d\left(x_{n}, x_{n+1}\right)\right)=0 .
$$

From (2.4) we have

$$
\left[d\left(x_{n}, x_{n+1}\right)\right]^{h} F\left(d\left(x_{n}, x_{n+1}\right)\right)-\left[d\left(x_{n}, x_{n+1}\right)\right]^{h} F\left(d\left(x_{0}, x_{n+1}\right)\right) \leqslant-n \tau\left[d\left(x_{n}, x_{n+1}\right)\right]^{h} \leqslant 0 .
$$

On taking limit as $n \rightarrow \infty$ we obtain

$$
\lim _{n \rightarrow \infty} n\left[d\left(x_{n}, x_{n+1}\right)\right]^{h}=0
$$

Hence $\lim _{n \rightarrow \infty} n^{\frac{1}{h}} d\left(x_{n}, x_{n+1}\right)=0$ and there exists $n_{1} \in \mathbb{N}$ such that $n^{\frac{1}{h}} d\left(x_{n}, x_{n+1}\right) \leqslant 1$ for all $n \geqslant n_{1}$. So we have

$$
d\left(x_{n}, x_{n+1}\right) \leqslant \frac{1}{n^{1 / h}}
$$

for all $n \geqslant n_{1}$. Now consider $m, n \in \mathbb{N}$ such that $m>n \geqslant n_{1}$, we have

$$
d\left(x_{n}, x_{m}\right) \leqslant d\left(x_{n}, x_{n+1}\right)+d\left(x_{n+1}, x_{n+2}\right)+\cdots+d\left(x_{m-1}, x_{m}\right) \leqslant \sum_{i=n}^{\infty} \frac{1}{i^{1 / h}} .
$$

By the convergence of the series $\sum_{i=1}^{\infty} \frac{1}{i^{1 / h}}$, we get $d\left(x_{n}, x_{m}\right) \rightarrow 0$ as $n, m \rightarrow \infty$. Therefore $\left\{x_{n}\right\}$ is a Cauchy sequence in $X$. The completeness of $(X, d)$ ensures that there exists $u \in X$ such that, $\lim _{n \rightarrow \infty} x_{n}=u$. Now, we prove that $u \in[T u]_{\alpha_{T}(u)}$. We suppose on the contrary that $u \notin[T u]_{\alpha_{T}(u)}$, then there exists an $n_{0} \in \mathbb{N}$ and a subsequence $\left\{x_{n_{k}}\right\}$ of $\left\{x_{n}\right\}$ such that $d\left(x_{2 n_{k}+1},[T u]_{\alpha_{T}(u)}\right)>0$ for all $n_{k} \geqslant n_{0}$. Since $\mathrm{d}\left(\mathrm{x}_{2 \mathrm{n}_{\mathrm{k}}+1},[\mathrm{Tu}]_{\alpha_{\mathrm{T}}(\mathfrak{u})}\right)>0$ for all $\mathrm{n}_{\mathrm{k}} \geqslant \mathrm{n}_{0}$, so by Lemma 1.5, $\left(\mathrm{F}_{1}\right)$, and (2.1), we have

$$
\begin{aligned}
\tau+F\left[d\left(x_{2 n_{k}+1},[T u]_{\alpha_{T}(u)}\right)\right] & \leqslant \tau+F\left[H\left(\left[S x_{2 n_{k}}\right]_{\alpha_{S}\left(x_{2 n_{k}}\right)},[T u]_{\alpha_{T}(u)}\right)\right] \\
& \leqslant F\left(d\left(x_{2 n_{k}}, u\right)\right)+\operatorname{Lin}\left\{\begin{array}{c}
d\left(x_{2 n_{k}},\left[S x_{2 n_{k}}\right]_{\alpha_{S}\left(x_{2 n_{k}}\right)}\right), d\left(u,[T u]_{\alpha_{T}(u)}\right), \\
d\left(x_{2 n_{k}},[T u]_{\alpha_{T}(u)}\right), d\left(u,\left[S x_{2 n_{k}}\right]_{\alpha_{S}\left(x_{2 n_{k}}\right)}\right)
\end{array}\right\} \\
& \leqslant F\left(d\left(x_{2 n_{k}}, u\right)\right)+\operatorname{Lin}\left\{\begin{array}{c}
d\left(x_{2 n_{k}}, u\right), d\left(x_{2 n_{k}}, x_{2 n_{k}+1}\right), d\left(u,[T u]_{\alpha_{T}(u)}\right), \\
d\left(x_{2 n_{k}},[T u]_{\alpha_{T}(u)}\right), d\left(u, x_{2 n_{k}+1}\right)
\end{array}\right\},
\end{aligned}
$$

which further implies that

$$
\begin{aligned}
F\left[d\left(x_{2 n_{k}+1},[T u]_{\alpha_{T}(u)}\right)\right] & \leqslant F\left(d\left(x_{2 n_{k}}, u\right)\right)+\min \left\{\begin{array}{c}
d\left(x_{2 n_{k}}, u\right), d\left(x_{2 n_{k}}, x_{2 n_{k}+1}\right), d\left(u,[T u]_{\alpha T}(u)\right), \\
d\left(x_{2 n_{k}},[T u]_{\alpha_{T}(u)}\right), d\left(u, x_{2 n_{k}+1}\right)
\end{array}\right\}-\tau \\
& <F\left(d\left(x_{2 n_{k}}, u\right)\right)+\min \left\{\begin{array}{c}
d\left(x_{2 n_{k}}, u\right), d\left(x_{2 n_{k}}, x_{2 n_{k}+1}\right), d\left(u,[T u]_{\alpha_{T}(u)}\right), \\
d\left(x_{2 n_{k}},[T u]_{\alpha_{T}(u)}\right), d\left(u, x_{2 n_{k}+1}\right)
\end{array}\right\} .
\end{aligned}
$$


Since $F$ is strictly increasing, we have

$$
d\left(x_{2 n_{k}+1},[T u]_{\alpha_{T}(u)}\right)<d\left(x_{2 n_{k}}, u\right)+\min \left\{\begin{array}{c}
d\left(x_{2 n_{k}}, u\right), d\left(x_{2 n_{k}}, x_{2 n_{k}+1}\right), d\left(u,[T u]_{\alpha_{T}(u)}\right), \\
d\left(x_{2 n_{k},},[T u]_{\alpha_{T}(u)}\right), d\left(u, x_{2 n_{k}+1}\right)
\end{array}\right\} .
$$

Letting $n \rightarrow \infty$, we have

$$
\mathrm{d}\left(\mathrm{u},[\mathrm{Tu}]_{\alpha_{\mathrm{T}}(\mathrm{u})}\right) \leqslant 0 .
$$

Hence $u \in[T u]_{\alpha_{T}(u)}$. Similarly, one can easily prove that $u \in[S u]_{\alpha_{S}(u)}$. Thus $u \in[S u]_{\alpha_{S}(u)} \cap[T u]_{\alpha_{T}(u)}$.

Theorem 2.2. Let $(X, d)$ be a complete metric space and let $S, T$ be fuzzy mappings from $X$ into $\mathfrak{I}(X)$ and for each $x \in X$, there exist $\alpha_{S}(x), \alpha_{T}(y) \in(0,1]$ such that $[S x]_{\alpha_{S}(x)},[T y]_{\alpha_{T}(y)}$ are nonempty, closed, and bounded subsets of $X$. If there exist some $F \in F$ and $\tau>0$ such that

$$
\tau+F\left(H\left([S x]_{\alpha_{S}(x)},[T y]_{\alpha_{T}(y)}\right)\right) \leqslant F(d(x, y))
$$

for all $x, y \in X$ with $\mathrm{H}\left([S x]_{\alpha_{S}(x)},[T y]_{\alpha_{T}(y)}\right)>0$, then there exists some $u \in[S u]_{\alpha_{S}(u)} \cap[\mathrm{Tu}]_{\alpha_{T}(u)}$.

Proof. Taking $\mathrm{L}=0$ in Theorem 2.1.

Corollary 2.3. Let $(X, d)$ be a complete metric space and let $\mathrm{S}$ be fuzzy mapping from $\mathrm{X}$ into $\mathfrak{I}(\mathrm{X})$ and for each $x \in X$, there exist $\alpha_{S}(x), \alpha_{S}(y) \in(0,1]$ such that $[S x]_{\alpha_{S}(x)},[S y]_{\alpha_{S}(y)}$ are nonempty, closed, and bounded subsets of $\mathrm{X}$. If there exist some $\mathrm{F} \in \digamma, \tau>0$ and $\mathrm{L} \geqslant 0$ such that

$$
\tau+F\left(H\left([S x]_{\alpha_{S}(x)},[S y]_{\alpha_{S}(y)}\right)\right) \leqslant F(d(x, y))+L(M(x, y))
$$

for all $x, y \in X$ with $\mathrm{H}\left([S x]_{\alpha_{S}(x)},[S y]_{\alpha_{S}(y)}\right)>0$, where

$$
M(x, y)=\min \left\{d\left(x,[S x]_{\alpha_{S}(x)}\right), d\left(y,[S y]_{\alpha_{S}(y)}\right), d\left(x,[S y]_{\alpha_{S}(y)}\right), d\left(y,[S x]_{\alpha_{S}(x)}\right)\right\},
$$

then there exists some $\mathrm{u} \in[\mathrm{Su}]_{\alpha_{\mathrm{S}}(\mathrm{u})}$.

Proof. Taking $\mathrm{S}=\mathrm{T}$ in Theorem 2.1.

Corollary 2.4. Let $(X, d)$ be a complete metric space and let $S$ be fuzzy mapping from $X$ into $\mathfrak{I}(X)$ and for each $x \in X$, there exist $\alpha_{S}(x), \alpha_{S}(y) \in(0,1]$ such that $[S x]_{\alpha_{S}(x)},[S y]_{\alpha_{S}(y)}$ are nonempty, closed, and bounded subsets of $\mathrm{X}$. If there exist some $\mathrm{F} \in \digamma$ and $\tau>0$ such that

$$
\tau+F\left(H\left([S x]_{\alpha_{S}(x)},[S y]_{\alpha_{S}(y)}\right)\right) \leqslant F(d(x, y))
$$

for all $x, y \in X$ with $\mathrm{H}\left([S x]_{\alpha_{S}(x)},[S y]_{\alpha_{S}(y)}\right)>0$, then there exists some $u \in[S u]_{\alpha_{S}(u)}$.

Proof. Taking $\mathrm{S}=\mathrm{T}$ and $\mathrm{L}=0$ in Theorem 2.1.

Corollary 2.5. Let $(\mathrm{X}, \mathrm{d})$ be a complete metric space and let $\mathrm{A}, \mathrm{B}: \mathrm{X} \rightarrow \mathrm{CB}(\mathrm{X})$ be multivalued mappings. If there exist some $\mathrm{F} \in \digamma, \tau>0$, and $\mathrm{L} \geqslant 0$ such that

$$
\tau+\mathrm{F}(\mathrm{H}(\mathrm{Ax}, \mathrm{By})) \leqslant \mathrm{F}(\mathrm{d}(\mathrm{x}, \mathrm{y}))+\mathrm{LM}(\mathrm{x}, \mathrm{y})
$$

for all $\mathrm{x}, \mathrm{y} \in \mathrm{X}$ with $\mathrm{H}(\mathrm{Ax}, \mathrm{By})>0$, where

$$
M(x, y)=\min \{d(x, A x), d(y, B y), d(x, B y), d(y, A x)\},
$$

then there exists some $\mathrm{u} \in \mathrm{A} u \cap \mathrm{Bu}$. 
Proof. Consider a mapping $\alpha: X \rightarrow(0,1]$ and a pair of fuzzy mappings $S, T: X \rightarrow \Im(X)$ defined by

$$
S(x)(t)=\left\{\begin{array}{ll}
\alpha(x), & \text { if } t \in A x, \\
0, & \text { if } t \notin A x,
\end{array} \text { and } T(x)(t)= \begin{cases}\alpha(x), & \text { if } t \in B x, \\
0, & \text { if } t \notin B x .\end{cases}\right.
$$

Then

$$
[S x]_{\alpha(x)}=\{t: S(x)(t) \geqslant \alpha(x)\}=A x \text { and } \quad[T x]_{\alpha(x)}=\{t: T(x)(t) \geqslant \alpha(x)\}=B x .
$$

Thus, Theorem 2.1 can be applied to obtain $u \in X$ such that

$$
u \in[S u]_{\alpha_{S}(u)} \cap[T u]_{\alpha_{T}(u)}=A u \cap B u .
$$

Corollary 2.6. Let $(\mathrm{X}, \mathrm{d})$ be a complete metric space and let $\mathrm{A}, \mathrm{B}: \mathrm{X} \rightarrow \mathrm{CB}(\mathrm{X})$ be multivalued mappings. If there exists some $\mathrm{F} \in \digamma$ and $\tau>0$ such that

$$
\tau+F(H(A x, B y)) \leqslant F(d(x, y))
$$

for all $\mathrm{x}, \mathrm{y} \in \mathrm{X}$ with $\mathrm{H}(\mathrm{Ax}, \mathrm{By})>0$, then there exists some $\mathrm{u} \in \mathrm{Au} \cap \mathrm{Bu}$.

Proof. Taking $\mathrm{L}=0$ in Theorem 2.5.

Corollary 2.7. Let $(\mathrm{X}, \mathrm{d})$ be a complete metric space and let $\mathrm{A}: \mathrm{X} \rightarrow \mathrm{CB}(\mathrm{X})$ be multivalued mapping. If there exists some $\mathrm{F} \in \digamma, \tau>0$ and $\mathrm{L} \geqslant 0$ such that

$$
\tau+F(H(A x, A y)) \leqslant F(d(x, y))+L M(x, y)
$$

for all $\mathrm{x}, \mathrm{y} \in \mathrm{X}$ with $\mathrm{H}(\mathrm{Ax}, \mathrm{Ay})>0>0$, where

$$
M(x, y)=\min \{d(x, A x), d(y, A y), d(x, A y), d(y, A x)\},
$$

then there exists some $u \in A u$.

Proof. Taking $\mathrm{A}=\mathrm{B}$ in Theorem 2.5.

Corollary 2.8. Let $(\mathrm{X}, \mathrm{d})$ be a complete metric space and let $\mathrm{A}: \mathrm{X} \rightarrow \mathrm{CB}(\mathrm{X})$ be multivalued mapping. If there exist some $\mathrm{F} \in \digamma$ and $\tau>0$ such that

$$
\tau+F(H(A x, A y)) \leqslant F(d(x, y))
$$

for all $x, y \in X$ with $\mathrm{H}(A x, A y)>0$, then there exists some $u \in A u$.

Proof. Taking $\mathrm{A}=\mathrm{B}$ and $\mathrm{L}=0$ in Theorem 2.5.

Theorem 2.9. Let $(X, d)$ be a complete metric linear space and let $\mathrm{S}, \mathrm{T}: \mathrm{X} \rightarrow \mathrm{W}(\mathrm{X})$ be fuzzy mappings. If there exist some $\mathrm{F} \in \digamma, \tau>0$, and $\mathrm{L} \geqslant 0$ such that

$$
\tau+F\left(d_{\infty}(S(x), T(y))\right) \leqslant F(p(x, y))+L M(x, y)
$$

for all $\mathrm{x}, \mathrm{y} \in \mathrm{X}$ with $\mathrm{d}_{\infty}(\mathrm{S}(\mathrm{x}), \mathrm{T}(\mathrm{y}))>0$, where

$$
M(x, y)=\min \{p(x, S(x)), p(y, T(y)), p(x, T(y)), p(y, S(x))\},
$$

then there exists some $\mathrm{u} \in \mathrm{X}$ such that $\{\mathrm{u}\} \subset \mathrm{S}(\mathrm{u})$ and $\{\mathrm{u}\} \subset \mathrm{T}(\mathrm{u})$.

Proof. Let $x \in X$, then by Lemma 1.5 there exists $y \in X$ such that $y \in[S x]_{1}$. Similarly, we can find $z \in X$ such that $z \in[T x]_{1}$. It follows that for each $x \in X,[S x]_{\alpha(x)},[T x]_{\alpha(x)}$ are nonempty, closed, and bounded 
subsets of $X$. As $\alpha(x)=\alpha(y)=1$, by the definition of a $d_{\infty}$-metric for fuzzy sets, we have

$$
H\left([S x]_{\alpha(x)},[T y]_{\alpha(x)}\right) \leqslant d_{\infty}(S(x), T(y))
$$

for all $x, y \in X$. From $\left(F_{1}\right)$, we have

$$
\tau+F\left(H\left([S x]_{\alpha(x)},[T y]_{\alpha(x)}\right)\right) \leqslant \tau+F\left(d_{\infty}(S(x), T(y))\right) \leqslant F(p(x, y))+L M(x, y),
$$

where

$$
M(x, y)=\min \{p(x, S(x)), p(y, T(y)), p(x, T(y)), p(y, S(x))\}
$$

for all $x, y \in X$. Since $[S x]_{1} \subseteq[S x]_{\alpha}$ for each $\alpha \in(0,1]$. Therefore $d\left(x,[S x]_{\alpha}\right) \leqslant d\left(x,[S x]_{1}\right)$ for each $\alpha \in(0,1]$. It implies that $p(x, S(x)) \leqslant d\left(x,[S x]_{1}\right)$. Similarly, $p(x, T(x)) \leqslant d\left(x,[T x]_{1}\right)$. This further implies that for all $x, y \in X$,

$$
\tau+F\left(H\left([S x]_{1},[T y]_{1}\right)\right) \leqslant F(d(x, y))+\operatorname{LM}(x, y)
$$

where

$$
M(x, y)=\min \left\{d\left(x,[S x]_{1}\right), d\left(y,[T y]_{1}\right), d\left(x,[T y]_{1}\right), d\left(y,[S x]_{1}\right)\right\}
$$

Now, by Theorem 2.1, we obtain $u \in X$ such that $u \in[S u]_{1} \cap[T u]_{1}$, i.e., $\{u\} \subset T(u)$ and $\{u\} \subset S(u)$.

Corollary 2.10. Let $(X, d)$ be a complete metric linear space and let $S, T: X \rightarrow W(X)$ be fuzzy mappings. If there exists some $\mathrm{F} \in \digamma$ and $\tau>0$ such that

$$
\tau+F\left(d_{\infty}(S(x), T(y))\right) \leqslant F(p(x, y))
$$

for all $x, y \in X$ with $d_{\infty}(S(x), T(y))>0$, then there exists some $u \in X$ such that $\{u\} \subset S(u)$ and $\{u\} \subset T(u)$.

Proof. Taking $\mathrm{L}=0$ in Theorem 2.9.

In the following, we suppose that $\widehat{\mathrm{T}}$ (for details, see $[27,30]$ ) is the set-valued mapping induced by fuzzy mappings $T: X \rightarrow \Im(X)$, i.e.,

$$
\widehat{T}(x)(t)=\left\{y \in X: T(x)(y)=\max _{t \in X} T(x)(t)\right\} .
$$

Lemma 2.11 ([1]). Let $(X, d)$ be a metric space, $\mathrm{u} \in \mathrm{X}$, and $\mathrm{T}: \mathrm{X} \rightarrow \mathfrak{I}(\mathrm{X})$ be fuzzy mapping such that $\widehat{\mathrm{T} x}$ is non empty compact set for all $\mathrm{x} \in \mathrm{X}$. Then $\mathrm{u} \in \widehat{\mathrm{T}}(\mathrm{u})$ iff $\mathrm{T}(\mathrm{u})(\mathrm{u}) \geqslant \mathrm{T}(\mathrm{u})(\mathrm{x})$ for all $\mathrm{x} \in \mathrm{X}$.

Theorem 2.12. Let $(X, d)$ be a complete metric space and let $\mathrm{S}, \mathrm{T}: \mathrm{X} \rightarrow \mathfrak{I}(\mathrm{X})$ be fuzzy mappings such that for all $x \in X, \widehat{S}(x), \widehat{T}(x)$ are nonempty closed bounded subsets of $X$. If there exists some $F \in \digamma, \tau>0$ and $L \geqslant 0$ such that

$$
\tau+F(H(\widehat{S}(x), \widehat{T}(y))) \leqslant F(d(x, y))+\operatorname{LM}(x, y)
$$

for all $\mathrm{x}, \mathrm{y} \in \mathrm{X}$ with $\mathrm{H}(\widehat{\mathrm{S}}(\mathrm{x}), \widehat{\mathrm{T}}(\mathrm{y}))>0$, where

$$
M(x, y)=\min \{d(x, \widehat{S}(x)), d(y, \widehat{T}(y)), d(x, \widehat{T}(y)), d(y, \widehat{S}(x))\},
$$

then there exists a point $x^{*} \in X$ such that $S\left(x^{*}\right)\left(x^{*}\right) \geqslant S\left(x^{*}\right)(x)$ and $\mathrm{T}\left(x^{*}\right)\left(x^{*}\right) \geqslant T\left(x^{*}\right)(x)$ for all $x \in X$.

Proof. By Corollary 2.5, there exists $x^{*} \in X$ such that $x^{*} \in \widehat{S} x^{*} \cap \widehat{T} x^{*}$. Then by Lemma 2.11, we have

$$
S\left(x^{*}\right)\left(x^{*}\right) \geqslant S\left(x^{*}\right)(x) \text { and } T\left(x^{*}\right)\left(x^{*}\right) \geqslant T\left(x^{*}\right)(x)
$$

for all $x \in X$. 
Corollary 2.13. Let $(X, d)$ be a complete metric space and let $S, T: X \rightarrow \Im(X)$ be fuzzy mappings such that for all $x \in X, \widehat{S}(x), \widehat{T}(x)$ are nonempty closed bounded subsets of $X$. If there exists some $F \in \digamma$ and $\tau>0$ such that

$$
\tau+F(H(\widehat{S}(x), \widehat{T}(y))) \leqslant F(d(x, y))
$$

for all $x, y \in X$ with $\mathrm{H}(\widehat{S}(x), \widehat{T}(y))>0$, then there exists a point $x^{*} \in X$ such that $S\left(x^{*}\right)\left(x^{*}\right) \geqslant S\left(x^{*}\right)(x)$ and $\mathrm{T}\left(\mathrm{x}^{*}\right)\left(\mathrm{x}^{*}\right) \geqslant \mathrm{T}\left(\mathrm{x}^{*}\right)(\mathrm{x})$ for all $\mathrm{x} \in \mathrm{X}$.

Proof. Taking $\mathrm{L}=0$ in Theorem 2.12 .

Now we present a non trivial example to show the significance of the investigation of our main Theorem 2.1.

Example 2.14. Let $X=[0,1]$ and define $d: X \times X \rightarrow \mathbb{R}^{+}$as follows:

$$
d(x, y)=|x-y| .
$$

Then $(X, d)$ is a complete metric space. Define a pair of mappings $S, T: X \rightarrow \mathfrak{I}(X)$ for $\alpha \in[0,1]$ as follows.

For $x \in X$, we have

$$
S(x)(t)=\left\{\begin{array}{l}
\alpha, \quad \text { if } 0 \leqslant t \leqslant \frac{x}{30}, \\
\frac{\alpha}{2}, \quad \text { if } \frac{x}{30}<t \leqslant \frac{x}{20}, \\
\frac{\alpha}{3}, \quad \text { if } \frac{x}{20}<t \leqslant \frac{x}{10}, \\
\frac{\alpha}{5}, \quad \text { if } \frac{x}{10}<t \leqslant 1,
\end{array}, \quad \text { and } \quad T(x)(t)=\left\{\begin{array}{l}
\alpha, \quad \text { if } 0 \leqslant t \leqslant \frac{x}{60}, \\
\frac{\alpha}{3}, \quad \text { if } \frac{x}{60}<t \leqslant \frac{x}{40}, \\
\frac{\alpha}{4}, \quad \text { if } \frac{x}{40}<t \leqslant \frac{x}{20}, \\
\frac{\alpha}{7}, \quad \text { if } \frac{x}{20}<t \leqslant 1,
\end{array}\right.\right.
$$

such that

$$
[\mathrm{Tx}]_{\alpha}=\left[0, \frac{x}{60}\right], \quad[\mathrm{Sx}]_{\alpha}=\left[0, \frac{x}{30}\right] .
$$

Let $F(t)=\ln (t)$ and $L=0$. Then there exists some $\tau \in\left(0, \ln \frac{|y-x|}{\left|y-\frac{x}{2}\right| \frac{1}{30}}\right)$ such that

$$
\tau+F\left(H\left([S x]_{\alpha_{S}(x)},[T y]_{\alpha_{T}(y)}\right)\right) \leqslant F(d(x, y))
$$

for all $x, y \in X$ with $H\left([S x]_{\alpha_{S}(x)},[T y]_{\alpha_{T}(y)}\right)>0$. Thus all the conditions of Theorem 2.1 are satisfied to obtain $0 \in[\mathrm{S} 0]_{\alpha} \cap[\mathrm{T} 0]_{\alpha}$.

\section{Acknowledgment}

This article was funded by the Deanship of Scientific Research (DSR), University of Jeddah, Jeddah. Therefore, authors acknowledges with thanks DSR, UOJ for financial support

\section{References}

[1] H. M. Abu-Donia, Common fixed point theorems for fuzzy mappings in metric space under $\phi$-contraction condition, Chaos Solitons Fractals, 34 (2007), 538-543. 2.11

[2] H. Adibi, Y. J. Cho, D. O’Regan, R. Saadati, Common fixed point theorems in L-fuzzy metric spaces, Appl. Math. Comput., 182 (2006), 820-828. 1

[3] A. Ahmad, A. S. Al-Rawashdeh, A. Azam, Fixed point results for $\{\alpha, \xi\}$-expansive locally contractive mappings, J. Inequal. Appl., 2014 (2014), 10 pages. 1

[4] J. Ahmad, A. Al-Rawashdeh, A. Azam, New fixed point theorems for generalized F-contractions in complete metric spaces, Fixed Point Theory Appl., 2015 (2015), 18 pages. 1

[5] A. Al-Rawashdeh, J. Ahmad, Common fixed point theorems for JS-contractions, Bull. Math. Anal. Appl., 8 (2016), 12-22. 1 
[6] I. Altun, G. Durmaz, G. Minak, S. Romaguera, Multivalued almost F-contractions on complete metric spaces, Filomat, 30 (2016), 441-448. 1

[7] I. Altun, G. Minak, H. Dağ, Multivalued F-contractions on complete metric spaces, J. Nonlinear Convex Anal., 16 (2015), 659-666. 1

[8] S. C. Arora, V. Sharma, Fixed point theorems for fuzzy mappings, Fuzzy Sets and Systems, 110 (2000), 127-130. 1, 1.6

[9] Z. Aslam, J. Ahmad, N. Sultana, New common fixed point theorems for cyclic compatible contractions, J. Math. Anal., 8 (2017), 1-12.

[10] A. Azam, M. Arshad, P. Vetro, On a pair of fuzzy $\phi$-contractive mappings, Math. Comput. Modelling, 52 (2010), 207-214.

[11] A. Azam, I. Beg, Common fixed points of fuzzy maps, Math. Comput. Modelling, 49 (2009), 1331-1336. 1

[12] S. Banach, Sur les opérations dans les ensembles abstraits et leur application aux équations intégrales, Fund. Math., 3 (1922), 133-181. 1

[13] V. Berinde, Approximating fixed points of weak contractions using the Picard iteration, Nonlinear Anal. Forum, 9 (2004), 43-53. 1, 1.1

[14] V. Berinde, General constructive fixed point theorems for Ćirić-type almost contractions in metric spaces, Carpathian J. Math., 24 (2008), 10-19. 1, 1.2

[15] R. K. Bose, D. Sahani, Fuzzy mappings and fixed point theorems, Fuzzy Sets and Systems, 21 (1987), 53-58. 1

[16] S. S. Chang, Y. J. Cho, B. S. Lee, J. S. Jung, S. M. Kang, Coincidence point theorems and minimization theorems in fuzzy metric spaces, Fuzzy Sets and Systems, 88 (1997), 119-127.

[17] Y. J. Cho, N. Petrot, Existence theorems for fixed fuzzy points with closed $\alpha$-cut sets in complete metric spaces, Commun. Korean Math. Soc., 26 (2011), 115-124. 1

[18] S. Heilpern, Fuzzy mappings and fixed point theorem, J. Math. Anal. Appl., 83 (1981), 566-569. 1

[19] A. Hussain, New approach of F-contraction involving fixed point on a closed ball, Turkish J. Anal. Number Theory, 4 (2016), 159-163. 1

[20] N. Hussain, J. Ahmad, A. Azam, On Suzuki-Wardowski type fixed point theorems, J. Nonlinear Sci. Appl., 8 (2015), 1095-1111.

[21] N. Hussain, A. E. Al-Mazrooei, J. Ahmad, Fixed point results for generalized $(\alpha-\eta)-\Theta$ contractions with applications, J. Nonlinear Sci. Appl., 10 (2017), 4197-4208.

[22] S. U. Khan, M. Arshad, A. Hussain, M. Nazam, Two new types of fixed point theorems for F-contraction, J. Adv. Stud. Topol., 7 (2016), 251-260.

[23] G. Minak, I. Altun, S. Romaguera, Recent developments about multivalued weakly Picard operators, Bull. Belg. Math. Soc. Simon Stevin, 22 (2015), 411-422. 1

[24] S. B. Nadler Jr., Multi-valued contraction mappings, Pacific J. Math., 30 (1969), 475-478. 1.5

[25] D. Qiu, L. Shu, Supremum metric on the space of fuzzy sets and common fixed point theorems for fuzzy mappings, Inform. Sci., 178 (2008), 3595-3604. 1

[26] R. A. Rashwan, M. A. Ahmed, Common fixed point theorems for fuzzy mappings, Arch. Math. (Brno), 38 (2002), 219-226. 1

[27] R. Saadati, S. M. Vaezpour, Y. J. Cho, Quicksort algorithm: application of a fixed point theorem in intuitionistic fuzzy quasi-metric spaces at a domain of words, J. Comput. Appl. Math., 228 (2009), 219-225. 2

[28] N. A. Secelean, Iterated function systems consisting of F-contractions, Fixed Point Theory Appl., 2013 (2013), 13 pages. 1

[29] D. Wardowski, Fixed points of a new type of contractive mappings in complete metric spaces, Fixed Point Theory Appl., 2012 (2012), 6 pages. 1

[30] S.-S. Zhang, Fixed point theorems for fuzzy mappings, II, (Chinese) ; translated from Appl. Math. Mech., 7 (1986), 133-138, Appl. Math. Mech. (English Ed.), 7 (1986), 147-152. 1, 2 